\title{
Modelling Exchange Rate Volatility using GARCH Models: Empirical Evidence from Arab Countries
}

\author{
Suliman Zakaria Suliman Abdalla \\ Assistant Professor, Department of Quantitative Analysis, College of Business Administration \\ King Saud University, Riyadh, Kingdom of Saudi Arabia \\ Tel: 96-65-6084-7037Ｅ-mail: sulabdalla@ksu.edu.sa
}

Received: November 24, 2011

Accepted: December 23, $2011 \quad$ Published: March 1, 2012

doi:10.5539/ijef.v4n3p216

URL: http://dx.doi.org/10.5539/ijef.v4n3p216

\begin{abstract}
This paper considers the generalized autoregressive conditional heteroscedastic approach in modelling exchange rate volatility in a panel of nineteen of the Arab countries using daily observations over the period of $1^{\text {st }}$ January 2000 to $19^{\text {th }}$ November 2011. The paper applies both symmetric and asymmetric models that capture most common stylized facts about exchange rate returns such as volatility clustering and leverage effect. Based on the GARCH( 1,1$)$ model, the results show that for ten out of nineteen currencies the sum of the estimated persistent coefficients exceed one, implying that volatility is an explosive process, in contrast, it is quite persistent for seven currencies, a result which is required to have a mean reverting variance process. Furthermore, the asymmetrical EGARCH $(1,1)$ results provide evidence of leverage effect for majority of currencies, indicating that negative shocks imply a higher next period volatility than positive shocks. Finally, the paper concludes that the exchange rates volatility can be adequately modelled by the class of GARCH models.
\end{abstract}

Keywords: Exchange rate volatility, Heteroscedasticity, GARCH model, Volatility clustering, Leverage effect

\section{Introduction}

Over the last few decades, exchange rate movements and fluctuations have become an important subject of macroeconomic analysis and have received a great deal of interest from academics, financial economists and policy makers, particularly after the collapse of the Bretton Woods agreement of fixed exchange rates among major industrial countries. Since then, there has been an extensive debate about the topic of exchange rate volatility and its potential influence on welfare, inflation, international trade and degree of external sector competitiveness of the economy and also its role in security valuation, investment analysis, profitability and risk management. Consequently, a number of models have been developed in empirical finance literature to investigate this volatility across different regions and countries. Well known and frequently applied models to estimate exchange rate volatility are the autoregressive conditional heteroscedastic (ARCH) model advanced by Engle (1982) and generalized (GARCH) model developed independently by Bollerslev (1986) and Taylor (1986).

The issue of modelling exchange rate volatility has gained considerable importance in the research studies since 1973, when many countries shifted towards floating exchange rate from fixed exchange rate regime. Part of these studies were conducted to understand the behavior of exchange rate and to explain the sources of its movements and fluctuations. Although, there is no consensus in the literature regarding the factors that influence exchange rate volatility but, generally, it could be explained largely by macroeconomic variables. Many researches indicate some connection between exchange rate volatility and news or information on other macroeconomic fundamentals (including inflation, interest rates, money supply and GDP), see for example, Hartman (1972), De Grauwe (1988), Asseery and Peel (1991), Choi and Prasad (1995), Andersen and Bollerslev (1998), Arize et al. (2000), McKenzie and Faff (2004), Engel and Kenneth (2005), Evans and Lyons (2005), Laakkonen (2007), Lubik and Frank (2007), Mark (2009) and Pavasuthipaisit (2010).

On the other hand, many empirical studies have risen significantly in recent years to investigate the characteristics of exchange rate volatility in the context of time series analysis of financial returns such as leverage effect and volatility clustering and persistence. For example, Friedman and Stoddard (1982), Meese and Rogoff (1983), Milhoj (1987), Taylor (1987), Hsieh (1989), Lastrapes (1989), Bollerslev (1990), Pesaran and Robinson (1993), Jorion (1995), McKenzie (1997), Tse and Tsui (1997) Brooks and Burke (1998), Longmore and Robinson (2004), Wang (2006), Yoon and Lee (2008), Hamadu and Adeleke (2009), and Fiser and Roman (2010) find evidence of volatility clustering and persistence which mean that large and small values in the log-returns tend to occur in clusters, and 
also find evidence of asymmetric effects in exchange rate returns which means downward movements (depreciation) is always followed by higher volatility and come to conclusion that GARCH models and their many extensions were successful in modelling and forecasting exchange rates volatility. (Note 1)

Although there have been an extensive empirical studies focusing on modelling and estimating exchange rate volatility in developed countries by applying different specifications, little attention has been paid in developing countries, and to the best of my knowledge, empirical research on the topic of volatility of exchange rate is fragmented as there is no work that compares the ability of different volatility models in the different Arab countries.

The main objective of this paper is to investigate volatility characteristics of exchange rate in selected Arab countries using daily observations over the period of $1^{\text {st }}$ January 2000 to $19^{\text {th }}$ November 2011 . The rest of this paper is organized as follows. Section 2 provides a brief review of exchange rate regimes and stylized facts about exchange rate volatility and section 3 describes the data used for investigation. Section 4 presents the methodology, while section 5 presents the empirical results, and finally section 6 concludes the paper.

\section{Exchange Rate Volatility, Regimes and Stylized Facts about Volatility of Exchange Rate}

\subsection{Exchange Rate Volatility}

Exchange rate volatility is a measure of the fluctuations in an exchange rate. It is also known as a measure of risk, whether in asset pricing, portfolio optimization, option pricing, or risk management, and presents a careful example of risk measurement, which could be the input to a variety of economic decisions. It can be measured on an hourly, daily, weekly, monthly or annual basis. Based on the assumption that changes in an exchange rate follow a normal distribution, volatility provides an idea of how much the exchange rate can change within a given period. Volatility of an exchange rate, just like that of other financial assets, is usually calculated from the standard deviation of movements of exchange rates. Clearly, it is unobservable variable and thus its measure is a matter of serious contention. Consequently the literature is not unanimous as to which measure is most appropriate. Recent literature, however, seems to be increasingly adopting the use of Bollerslev's generalized autoregressive conditional heteroscedasticity $(\mathrm{GARCH})$ models

Two measures of volatility are commonly employed in financial calculations; historical and implied volatility. Historical volatility is calculated from the past values of an exchange rate. Given a series of past daily exchange rates, we can calculate the standard deviation of the daily price changes and then the annual volatility of the exchange rate. Historical volatility provides a good assessment of possible future changes when the financial markets and economies have not gone through structural changes. Implied volatility is a forward looking measure of volatility and is calculated from the market participants estimates of what is likely to happen in the future. More precisely, implied volatility is estimated from the quoted price of a currency option when the values of all other determinants of the price of an option are known. The basis for this calculation is the Black Scholes option pricing model, according to which the price of an option is determined by the following: the current price of the asset (the exchange rate or a stock or a commodity), the strike price at which the option can be exercised, the remaining time for the maturity of the option, the risk free interest rate, and the volatility of the asset (or the exchange rate.). Exchange rate volatility, like the volatility of any other financial asset, changes in response to information. Currency traders are sensitive to information that might influence the value of one currency in terms of another. The most important information is that about the macroeconomic performance of the economies behind the two currencies. Changes in the levels of uncertainty about the future of either economy will cause traders to become restless and less willing to hold a particular currency. Uncertainty about the future is the most important reason for the change in the volatility in the currency markets. Changes in the proportions of hedgers versus speculators can also change the volatility of a currency. Central banks can also influence the volatility of their currencies with their announcements of their intentions to either intervene or otherwise in the markets for their currencies. While it is commonly believed that central banks can influence the value of their currency at most in the short run, they can certainly cause a change in the volatility.

\subsection{Exchange Rate Regimes}

Exchange rate systems are classified on the basis of the flexibility that the monetary authorities show towards fluctuations in the exchange rates and have been traditionally divided into two categories, namely systems with a fixed exchange rate and systems with a flexible exchange rate. In the former system the exchange rate is usually a political decision, in the latter the prices are determined by the market forces, in accordance with demand and supply. These systems are often referred to as Fixed Peg (sometimes also described as "hard peg") and Floating systems. But as usual, between these two extreme positions there exists also an intermediate range of different systems with limited flexibility, usually referred to as "soft pegs". In the following, some of these systems are described in short to show which possibilities exist to choose an exchange rate regime from8. 


\subsubsection{Fixed Pegs}

A fixed peg regime exists when the exchange rate of the home currency is fixed to an anchor currency. This is the case with economies having currency boards or with no separate national currency of their own. Countries do not have a separate national currency, either when they have formally dollarized, or when the country is a member of a currency union, for example Euro. The IMF categorizes these two processes as "Exchange Arrangement with No Separate Le-gal Tender".

\subsubsection{Floating Regimes}

Floating exchange rate regimes consist of independent floating and managed floating systems. In independent floating systems the exchange rate is market determined and monetary policy usually functions without exchange rate considerations. Foreign exchange interventions are rare and meant to prevent undue fluctuations. But no attempt is undertaken to achieve/maintain a particular rate. Managed floating systems usually let the market take its own course but the monetary authorities intervene in the market to "manage" the exchange rate, if needed, to prevent high volatilities and to stimulate growth, without committing to a particular exchange rate level. The IMF calls this practice a "Managed Floating With No Predetermined Path for the Exchange Rate".

\subsubsection{Intermediate Regimes}

Intermediate exchange rate regimes consist of an array of differing systems allowing a varying degree of flexibility, such as conventional fixed exchange rate pegs, crawling pegs and exchange rate bands. For more details about exchange rate regimes see Tiwari (2003).

\subsection{Stylized Facts about Volatility of Exchange Rates}

Financial time series such as, exchange rates, stock returns and other financial series are known to exhibit certain stylized patterns which are crucial for correct model specification, estimation and forecasting (Note 2). Since the early work of Mandelbrot (1963) and Fama (1965), researchers have documented empirical regularities regarding theses series. Due to a large body of empirical evidence, many of the regularities can be considered stylized facts. The most common stylized facts are the following:

\subsubsection{Fat Tails}

When the distribution of financial time series such as exchange rate returns is compared with the normal distribution, fatter tails are observed. This observation is also referred to as excess kurtosis. The standardized fourth moment for a normal distribution is 3 whereas for many financial time series a value well above 3 is observed (Mandelbrot (1963) and Fama $(1963,1965)$ are the first studies to report this feature).

\subsubsection{Volatility Clustering and Persistence}

The second stylized fact is periods of volatility clustering which mean that large and small values in the log-returns tend to occur in clusters. i.e., the large changes tend to be followed by large changes and small changes tend to be followed by small changes. This was first put across by Mandelbrot (1963). When volatility is high it is likely to remain high and when it is low it is likely to remain low. Volatility clustering is nothing but accumulation or clustering of information. This feature reflects on the fact that news is clustered over time (Engle, 2004).

\subsubsection{Leverage Effects}

In financial markets, it is a stylized fact that a downward movement (depreciation) is always followed by higher volatility. This characteristic exhibited by percentage changes in financial data is termed leverage effects. According to past studies in this field, price movements are negatively correlated with volatility. Volatility is higher after negative shocks than after positive shocks of the same magnitude. This feature was first suggested by Black (1976) for stock returns. He attributed asymmetry to leverage effects. In this context, negative shocks increase predictable volatility in asset markets more than positive shocks. Another explanation of asymmetry is volatility feedback hypothesis. This in case of foreign market, a shock, which increases the volatility of the market, increases the risk of holding the currency (Longmore and Robinson, 2004). Empirical evidence on leverage effects can be found in Nelson (1991), Gallant, Rossi and Tauchen (1992, 1993), Campbell and Kyle (1993) and Engle and Ng (1993).

\subsubsection{Long Memory}

Especially for high-frequency data like exchange tares, volatility is highly persistent and there exists evidence of near unit root behaviour of the conditional variance process. This observation led to two propositions for modelling persistence: unit root or long memory process. (Longmore and Robinson, 2004).

\subsubsection{Co-movements in Volatility}

When looking at financial time series across different markets, such as looking at exchange rate returns for different 
currencies, we observe big movements in one currency being matched by big movements in another. This suggests the importance of multivariate models in modelling cross-correlations in different markets.

\subsubsection{Regular Events}

Regular events like holidays and weekends have effects on exchange rate volatility. Studies indicate that volatility of exchange rates returns or percentage changes is lower during weekends and holidays than during the trading week. Many studies attribute this phenomenon to the accumulative effects of information during weekends and holidays (Note 3).

\section{Data}

The data which will be used in modelling volatility of exchange rate in this paper are the daily returns of exchange rates on the United Arab Emirates dirham (AED), Bahraini Dinar (BHD), Djiboutian Franc (DJF), Algerian Dinar (DZD), Egyptian Pound (EGP), Iraqi Dinar (IQD), Jordanian Dinar (JOD), Kuwaiti Dinar (KWD), Lebanese Pound (LBP), Libyan Dinar (LYD), Moroccan Dirham (MAD), Mauritanian Ouguiya (MRO), Omani Rial (OMR), Qatari Riyal (QAR), Saudi Arabian Riyal (SAR), Somali Shilling (SOS), Syrian Pound (SYP), Tunisian Dinar (TND), and Yemeni Rial (YER), all against the US dollar. The data span from $1^{\text {st }}$ January 2000 to $19^{\text {th }}$ November 2011 resulting in a total of 4341 observation. All the data are sourced from www.oanda.com/currency/realtime series.

As in most of empirical finance literature, the variable to be modelled is percentage daily exchange rate return which is the first difference of the natural logarithm of the exchange rate and is given by the following equation:

$$
r_{t}=100 * \log \left(\frac{E_{t}}{E_{t-1}}\right)
$$

where $r_{t}$ is the daily percentage return to the exchange rate and $E_{t}$ and $E_{t-1}$ denote the exchange rate at the current day and previous day, respectively. Summary statistics of daily exchange rates are provided in Table 1

\section{Methodology}

This section discusses the competing GARCH models used to investigate volatility characteristics. In presenting these models, there are two distinct specifications, the first for the conditional mean and the other for the conditional variance. The models are estimated using maximum likelihood method under the assumption of Gaussian normal error distribution (Note 4). The log likelihood function is maximized using Marquardt numerical iterative algorithm to search for optimal parameters.

\subsection{Volatility Definition and Measurement}

It is useful, before starting the description of volatility models to give a brief explanation of the term volatility, at least for the purpose of clarifying the scope of this paper. Volatility refers to the spread of all likely outcomes of an uncertain variable. Typically, in financial markets, we are often concerned with the spread of asset returns. Statistically, volatility is often measured as the sample standard deviation:

$$
\hat{\sigma}=\sqrt{\frac{1}{T-1} \sum_{t=1}^{T}\left(r_{t}-\mu\right)^{2}}
$$

where $r_{t}$ is the return on day $\mathrm{t}$ and $\mu$ is the average return over the T-day period. Sometimes, variance, $\sigma^{2}$, is used also as a volatility measure. Volatility is related to, but not exactly the same as, risk. Risk is associated with undesirable outcome, whereas volatility as a measure strictly for uncertainty could be due to a positive outcome (Poon, 2005). This paper uses the variance as a measured of volatility.

\subsection{Testing for Heteroscedasticity}

One of the most important issues before applying the generalized autoregressive conditional heteroscedasticity (GARCH) methodology is to first examine the residuals of the returns series of exchange rate for evidence of heteroscedasticity. To test for this heteroscedasticity, the Lagrange Multiplier (LM) test proposed by Engle (1982) is applied.

In summary, the test procedure is performed by first obtaining the residuals $e_{t}$ from the ordinary least squares regression of the conditional mean equation which might be an autoregressive (AR) process, moving average (MA) process or a combination of AR and MA processes; i.e. (ARMA) process. For example, in ARMA $(1,1)$ process the conditional mean equation will be:

$$
r_{t}=\phi_{1} r_{t-1}+\varepsilon_{t}+\theta_{1} \varepsilon_{t-1}
$$


After obtaining the residuals $e_{t}$, the next step is to regress the squared residuals on a constant and q lags as in the following equation:

$$
e_{t}^{2}=\alpha_{0}+\alpha_{1} e_{t-1}^{2}+\alpha_{2} e_{t-2}^{2}+\ldots+\alpha_{q} e_{t-q}^{2}+v_{t}
$$

The null hypothesis that there is no ARCH effect up to order q can be formulated as:

$$
H_{0}: \alpha_{1}=\alpha_{2} . .=\alpha_{q}=0
$$

against the alternative:

$$
H_{1}: \alpha_{i}>0
$$

for at least one $\mathrm{i}=1,2, \ldots, \mathrm{q}$.

The test statistic for the joint significance of the q-lagged squared residuals is the number of observations times the $\mathrm{R}$-squared $\left(T R^{2}\right)$ from the regression. $T R^{2}$ is evaluated against $\chi^{2}(q)$ distribution. This is an asymptotically locally most powerful test (Rachev et al., 2007).

In this paper, an autoregressive moving average ARMA $(1,1)$ model for the conditional mean in the returns series is employed as an initial regression, then, test the null hypothesis that there are no ARCH effects in the residual series.

\subsection{Volatility Models}

\subsubsection{The Generalized Autoregressive Conditional Heteroscedastic (GARCH) Model}

The generalized autoregressive conditional heteroscedastic (GARCH) model is used in this paper to investigate the volatility clustering and persistence. The model has only three parameters that allows for an infinite number of squared errors to influence the current conditional variance (volatility). The conditional variance determined through GARCH model is a weighted average of past squared residuals. However, the weights decline gradually but they never reach zero. Essentially, the GARCH model allows the conditional variance to be dependent upon previous own lags. The general framework of this model, GARCH (p, q), is expressed by allowing the current conditional variance to depend on the first $p$ past conditional variances as well as the $q$ past squared innovations. That is,

$$
\sigma_{t}^{2}=\omega+\sum_{j=1}^{q} \alpha_{j} \varepsilon_{t-1}^{2}+\sum_{i=1}^{p} \beta_{i} \sigma_{t-1}^{2}
$$

where, $\mathrm{p}$ is the number of lagged $\sigma^{2}$ terms and $\mathrm{q}$ is the number of lagged $\varepsilon^{2}$ terms.

In this paper, the following simple specification - GARCH $(1,1)$ - is used:

$$
\begin{aligned}
& \text { Mean equation } r_{t}=\mu+\varepsilon_{t} \\
& \text { Variance equation } \sigma_{t}^{2}=\omega+\alpha_{1} \varepsilon_{t-1}^{2}+\beta_{1} \sigma_{t-1}^{2}
\end{aligned}
$$

where $\omega>0$ and $\alpha_{1} \geq 0$ and $\beta_{1} \geq 0$, and.

$r_{t}=$ return of the asset at time t.

$\mu=$ average returns.

$\varepsilon_{t}=$ residual returns, defined as:

$$
\varepsilon_{t}=\sigma_{t} z_{t}
$$

where $z_{t}$ is standardized residual returns (i.e. iid random variable with zero mean and variance 1 ), and $\sigma_{t}^{2}$ is conditional variance.

The constraints $\alpha_{1} \geq 0$ and $\beta_{1} \geq 0$ are needed to ensure $\sigma_{t}^{2}$ is strictly positive (Poon, 2005).

In this model, the mean equation is written as a function of constant with an error term. Since $\sigma_{t}^{2}$ is the one - period ahead forecast variance based on past information, it is called the conditional variance. The conditional variance equation specified as a function of three terms: (i) A constant term: $\omega$; (ii) News about volatility from the previous period, measured as the lag of the squared residuals from the mean equation: $\varepsilon_{t-1}^{2}$ (the ARCH term); and (iii) Last period forecast variance: $\sigma_{t-1}^{2}$ (the GARCH term).

The conditional variance equation models the time varying nature of volatility of the residuals generated from the mean equation. This specification is often interpreted in a financial context, where an agent or trader predicts this 
period's variance by forming a weighted average of a long term average (the constant), the forecast variance from last period (the GARCH term), and information about volatility observed in the previous period (the ARCH term). If the asset return was unexpectedly large in either the upward or the downward direction, then the trader will increase the estimate of the variance for the next period.

\subsubsection{The Exponential GARCH (EGARCH) model}

Even if the GARCH models successfully capture the thick tail returns, and the volatility clustering, they are poor models if one wishes to capture the leverage effect since the conditional variance is a function only of the magnitudes of the past values and not their sign. In financial time-series, it has been stated that volatility behaves differently depending on if a positive or negative shock occurs. This asymmetric relationship is called leverage effect, and describes how a negative shock causes volatility to rise more than if a positive shock with the same magnitude had occurred. To capture this asymmetry, different models have been developed and the one used in this paper is the EGARCH model. This model captures asymmetric responses of the time-varying variance to shocks and, at the same time, ensures that the variance is always positive. The model was developed by Nelson (1991). In the general form, the conditional variance is written as:

$$
\operatorname{Ln}\left(\sigma_{t}^{2}\right)=\omega+\sum_{j=1}^{p} \beta_{j} \operatorname{Ln}\left(\sigma_{t-j}^{2}\right)+\sum_{i=1}^{q} \alpha_{i}\left\{\left|\frac{\varepsilon_{t-i}}{\sigma_{t-i}}\right|-\sqrt{\frac{2}{\pi}}\right\}-\gamma_{i} \frac{\varepsilon_{t-i}}{\sigma_{t-i}}
$$

The EGARCH model is asymmetric because the level $\left|\varepsilon_{t-i}\right| \sigma_{t-i}$ is included with coefficient $\gamma_{i}$. Since this coefficient is typically negative, positive returns shocks generate less volatility than negative return shocks assuming other factors remains unchanged.

In macroeconomic analysis, financial markets and corporate finance, a negative shock usually implies bad news, leading to a more uncertain future. Consequently, for example, shareholders would require a higher expected return to compensate for bearing increased risk in their investment (Wang, 2003).

In order to capture asymmetric responses of the time-varying variance to shocks, the paper employs EGARCH $(1,1)$ model, which has the following specification:

$$
\begin{aligned}
& \text { Mean equation } \quad r_{t}=\mu+\varepsilon_{t} \\
& \text { Variance equation } \operatorname{Ln}\left(\sigma_{t}^{2}\right)=\omega+\beta_{1} \operatorname{Ln}\left(\sigma_{t-1}^{2}\right)+\alpha_{1}\left\{\left|\frac{\varepsilon_{t-1}}{\sigma_{t-1}}\right|-\sqrt{\frac{2}{\pi}}\right\}-\gamma \frac{\varepsilon_{t-1}}{\sigma_{t-1}}
\end{aligned}
$$

\section{Empirical Results}

\subsection{Descriptive Statistics of the Daily Returns of the Exchange Rates Series}

To specify the distributional properties of the daily returns of the exchange rates series, various descriptive statistics were calculated and reported in Table 2. As we can see from Table 2, Skewness and excess kurtosis are clearly observed for the daily returns for all currencies which indicate departure from normality (Note 5). Likewise, the Jarque-Bera (J-B) statistic, which is a test for normality, also confirms that the null hypothesis of normality for the daily returns should be rejected at the $1 \%$ significant level. In summary, all returns series do not conform to normal distribution but display positive skewness (the distribution has a long right tail) for AED, BHD, DJF, DZD, EGP, JOD, KWD, LYD, MAD, MUR, OMR, QAR, SYP and YER, and negative skewness (the distribution has a long left tail) for IQD, LBP, SAR, SOS and TND. In addition to that, a highly leptokurtic distribution is observed for all series. Moreover, Figure 1 presents the pattern of the exchange rate series and its returns for the currencies used.

To investigate whether the daily returns are stationary, the Augmented Dickey -Fuller (ADF) test (Dickey and Fuller, 1981) has been applied. The ADF test results in Table 2 strongly reject the null hypothesis of a unit root for all series.

\subsection{Results of Heteroscedasticity Test}

The results of examination the residuals for evidence of heteroscedasticity are summarized in Table 3. The ARCHLM test results provide strong evidence for rejecting the null hypothesis for all series except the case of Iraqi Dinar (IQD) and Libyan Dinar (LYD). Rejecting the null hypothesis indicates the existence of ARCH effects in the residuals series in the mean equation.

\subsection{Test of Asymmetry}

In order to investigate further the existence of leverage effect, sign and size bias tests for asymmetry in volatility proposed by Engle and $\mathrm{Ng}$ (1993) will be conducted (Note 6). These tests are commonly used to differentiate the effect of good and bad news on the predictability of stock returns volatility. In these tests, two sources of asymmetric 
response of variance are considered: the sign effect that is past shocks of different sign have a differentiated effect on the present volatility, and the size effect, that is past shocks of the same sign but different magnitudes have different effects on present variance. The following regression is performed:

$$
\hat{u}_{t}^{2}=\phi_{0}+\phi_{1} S_{t-1}^{-}+\phi_{2} S_{t-1}^{-} u_{t-1}+\phi_{3} S_{t-1}^{+} u_{t-1}+v_{t}
$$

where $S_{t-1}^{-}$is an indicator dummy that takes the value of 1 if $\hat{u}_{t-1}<0$ and zero otherwise. The t-ratios for $\phi_{1}, \phi_{2}$ and $\phi_{3}$ are the sign bias, the negative size bias, and the positive size bias test statistics, respectively. $v_{t}$ is $i i d$. Significance of $\phi_{1}$ indicates the presence of sign bias, meaning that the variance of returns is larger after a negative return than after a positive return. On the other hand, the significance of $\phi_{2}$ or $\phi_{3}$ indicate respectively negative and positive size bias, meaning that the variance is higher after a large (positive or negative) return than after a small (positive or negative) return and that the time-series is characterized by variance clustering. Engle and $\mathrm{Ng}$ show that a joint test for the size and sign bias, based on the Lagrange multiplier principal, formulated in the standard fashion by calculating $\mathrm{TR}^{2}$ from equation (12), which will asymptotically follow a $\chi^{2}$ distribution with 3 degrees of freedom under the null hypothesis of no asymmetric effects $\left(\phi_{1}=\phi_{2}=\phi_{3}=0\right)$. The results of this investigation are presented in Table 6.

As can be seen in Table 6 , the results show that $\phi_{1}, \phi_{2}$ and $\phi_{3}$ are statistically significant in most cases. Also, the results indicate that both $\phi_{2}$ and $\phi_{3}$ have the expected sign in most cases as $\phi_{2}$ is negative and $\phi_{3}$ positive, meaning that the volatility increases more after a shock of negative sign. However there are different effects according to the sign of past returns as we observe that the size bias coefficients $\phi_{2}$ and $\phi_{3}$ are different of each other. The significant negative size bias indicates that large negative returns induce higher subsequent squared returns, while positive size bias indicates that a positive return has a larger effect than a negative return. These results indicate that returns volatility exhibit asymmetric behavior, suggesting that the asymmetric volatility models are better suited for capturing the dynamics of volatility process in the data series.

\subsection{Estimation results of $\operatorname{GARCH}(1,1)$ Model}

The estimation results of GARCH $(1,1)$ model in Table 4 show that the first three coefficients $\omega$ (constant), ARCH term $(\alpha)$ and GARCH term $(\beta)$ are statistically significant at the $1 \%$ level and with expected sign for all returns series. The statistical significance of the coefficient $\alpha$ shows the presence of volatility clustering in GARCH $(1,1)$ model for all cases. Also the significance of both $\alpha$ and $\beta$ indicates that, lagged conditional variance and lagged squared disturbance have an impact on the conditional variance, in other words this means that news about volatility from the previous periods have an explanatory power on current volatility. Moreover, Table 4 also shows that; the sum of the two estimated ARCH and GARCH coefficients $\alpha+\beta$ (persistence coefficient) for the United Arab Emirates dirham (AED), Djiboutian franc (DJF), Algerian Dinar (DZD), Jordanian Dinar (JOD), Lebanese Pound (LBP), Qatari riyal (QAR), Saudi Arabian Riyal (SAR), Syrian Pound (SYP), Tunisian Dinar (TND), and Yemeni rial (YER) is larger than one, suggesting that the conditional variance is an explosive process. However, for the Bahraini Dinar (BHD), Egyptian Pound (EGP), Kuwaiti Dinar (KWD), Moroccan Dirham (MAD), Mauritanian ouguiya (MUR), Omani Rial (OMR), and Somali Shilling (SOS) returns, the sum of the ARCH and GARCH coefficients is very close to one which is required to have a mean reverting variance process, indicating that volatility shocks are quite persistent. This appears to show that the shocks to volatility are very high and will remain forever as the variances are not stationary under the GARCH model.The ARCH-LM test statistics did not exhibit additional ARCH effect. This shows that the variance equations are well specified.

\subsection{Estimation Results of EGARCH $(1,1)$ Model}

The asymmetrical EGARCH $(1,1)$ results in Table 5 indicate that all the estimated coefficients are statistically significant at the $1 \%$ confidence level. The parameter for the asymmetric volatility response $(\gamma)$ is negative and significant for all cases- except for the Jordanian Dinar (JOD)- indicating an asymmetric response for positive returns in the conditional variance equation. This result reflects the condition that volatility tends rise in response to positive spikes and fall in response to negative spikes. This lies counter to the usual expectation in stock markets where downward movements (falling returns) are followed by higher volatility than upward movements (increasing returns), that means the existence of leverage effects in the returns series during the study period. According to the ARCH-LM test results, there is no additional ARCH effect left. 


\section{Conclusions}

This paper has examined the daily returns of exchange rates series of nineteen Arab countries. The currencies considered are the United Arab Emirates dirham (AED), Bahraini Dinar (BHD), Djiboutian franc (DJF), Algerian Dinar (DZD), Egyptian Pound (EGP), Iraqi Dinar (IQD), Jordanian Dinar (JOD), Kuwaiti Dinar (KWD), Lebanese Pound (LBP), Libyan Dinar (LYD), Moroccan Dirham (MAD), Mauritanian ouguiya (MRO), Omani Rial (OMR), Qatari riyal (QAR), Saudi Arabian Riyal (SAR), Somali Shilling (SOS), Syrian Pound (SYP), Tunisian Dinar (TND), and Yemeni rial (YER), all against the US dollar. The data span from $1^{\text {st }}$ January 2000 to $19^{\text {th }}$ November 2011. The paper employs two univariate specifications of the generalized autoregressive conditional heteroscedastic (GARCH) model, including both symmetric and asymmetric models that capture most common stylized facts about exchange rate returns such as volatility clustering and leverage effect. The empirical results show that the conditional variance (volatility) is an explosive process for the ten of nineteen currencies, while it is quite persistent for seven currencies which is required to have a mean reverting variance process. Furthermore, the asymmetrical EGARCH $(1,1)$ results find evidence of leverage effects for all currencies - except for the Jordanian Dinar (JOD) indicating that negative shocks imply a higher next period conditional variance than positive shocks of the same magnitude. Finally, the paper concludes that the exchange rates volatility can be adequately modelled by the class of GARCH models.

\section{Acknowledgments}

The author is gratefully acknowledges the financial support provided by the Research Center at the College of Business Administration (King Saud University). I would also like to thank the editor of this journal as well as the two anonymous referees for their very helpful comments and suggestions.

\section{References}

Abraham, A., \& Ikenberry. D. (1994). The Individual Investor and the Weekend Effect. Journal of Financial and Quantitative Analysis, 29, 263-277. http://dx.doi.org/10.2307/2331225

Andersen, T.G., \& Bollerslev, T. (1998). Answering the Skeptics: Yes, Standard Volatility Models do Provide Accurate Forecasts. International Economic Review, 39, 885-905. http://dx.doi.org/10.2307/2527343

Arize, A.C., Osang T, \& Slottje D.J. (2000). Exchange-Rate Volatility and Foreign Trade: Evidence from 13 LDC's. Journal of Business \& Economic Statistics, 8(1), 10-17. http://dx.doi.org/10.2307/1392132

Asseery, \& D.A. Peel, (1991). The Effects of Exchange rate Volatility on Export: Some New Estimates. Economic Letters, 37, 173-177.

Black, F. (1976). Studies of Stock Market Volatility Changes. Proceedings of the American Statistical Association. Business and Economic Statistics Section, 177-181.

Bollerslev, T. (1990). Modelling the Coherence in Short-run Nominal Exchange Rates: A Multivariate Generalized ARCH Model. Review of Economics and Statistics, 72, 498-505. http://dx.doi.org/10.2307/2109358

Brooks, C., \& S. P. Burke, (1998). Forecasting exchange rate volatility using conditional variance models selected by information criteria. Economics Letters, 61, 273-278. http://dx.doi.org/10.1016/S0165-1765(98)00178-5

Cai, J., Y. Li, \& Y. Qi, (2006). The day-of-the-week effect: New evidence from the Chinese stock market. The Chinese Economy, 39, 71-88. http://dx.doi.org/10.2753/CES1097-1475390206

Campbell, J.Y., \& Kyle, A.S. (1993). Smart money, noise trading and stock price behaviour. Review of Economic Studies, 60, 1-34. http://dx.doi.org/10.2307/2297810

Choi, J. J., \& Prasad, A. M. (1995). Exchange Risk Sensitivity and its Determinants: A firm and Industry Analysis of US Multinationals. Financial Management, 24(3), 77-88. http://dx.doi.org/10.2307/3665559

De Grauwe, P. (1988). Exchange Rate Variability and the Slowdown in the growth of International Trade. IMF Staff Papers, 46 (3), 315-334.

Engel, Charles, \& Kenneth, D., West, (2005). Exchange Rate and Fundamentals. Journal of Political Economy, 113(3), 485-517. http://dx.doi.org/10.1086/429137

Engle, R.F., \& Ng, V.K. (1993). Measuring and testing the impact of news on volatility. Journal of Finance, 48, 1749-1801. http://dx.doi.org/10.2307/2329066

Enders, W. (2004). Applied Econometric Time Series, (2nd ed.). Wiley Series in Probability and Statistics.

Evans, M., \& Lyons, R. (1999). Order Flow and Exchange Rate Dynamics. NBER Working Paper W7317.

Fama, E.F. (1963). Mandelbrot and the stable paretian distribution. Journal of Business 36, 420-429. http://dx.doi.org/10.1086/294633 
Fama, E. F. (1965). The behavior of stock market prices. Journal of Business 38, 34-105. http://dx.doi.org/10.1086/294743

Fiser, Radovan, \& Roman Horvath, (2010). Central Bank Communication and Exchange Rate Volatility: A GARCH Analysis. Macroeconomics and Finance in Emerging Market Economies, 3(2), 25-31. http://dx.doi.org/10.1080/17520840903498099

Friedman, Daniel, \& Stoddard Vandersteel, (1982). Short-run fluctuations in foreign exchange rates: evidence from the data 1973-1979. Journal of international Economics, 13, 171-186. http://dx.doi.org/10.1016/0022-1996(82)90012-5

Gallant, A.R., Rossi, P.E. and Tauchen, G. (1992). Stock prices and volume. Review of Financial Studies 5, 199-242. http://dx.doi.org/10.1093/rfs/5.2.199

Gallant, A.R., Rossi, P.E., \&Tauchen, G. (1993). Nonlinear Dynamic Structures. Econometrica, 61, 871-907. http://dx.doi.org/10.2307/2951766

Hamadu, Dallah, \& Adeleke Ismaila, (2009). On Modelling the Nigerian Currency (naira) Exchange Rates against Major Regional and World Currencies. Journal OF Business and Economics, 2, 42-52.

Hartman, R. (1972). The Effects of Price and Cost Uncertainty on Investment. Journal of Economic Theory, 5(10), 258-266. http://dx.doi.org/10.1016/0022-0531(72)90105-6

Hsieh, D.A. (1989). Modeling heteroscedasticity in daily foreign-exchange rates. Journal of Business \& Economic Statistics, 7, 307-317. http://dx.doi.org/10.2307/1391528

Jorion, Philippe. (1995). Predicting volatility in the foreign exchange market. The Journal of Finance, 1, 507-528. http://dx.doi.org/10.2307/2329417

Kim, S., McKenzie, M.D., \& Faff, R.W. (2004). Macroeconomic News Announcements and the Role of Expectations: Evidence for US Bonds, Stocks and Foreign Exchange Markets. Journal of Multinational Financia Management,14, 217-232. http://dx.doi.org/10.1016/j.mulfin.2003.02.001

Laakkonen, H. (2007). Impact of Macroeconomic News on Exchange Rate Volatility. Finnish conomic Papers, 20, 23-40.

Lastrapes, William, D. (1989). Exchange rate volatility and U.S. monetary policy: An ARCH application. Journal of Money, Credit, and Banking, 21, 66-77. http://dx.doi.org/10.2307/1992578

Longmore, R., \& W. Robinson. (2004). Modelling and Forecasting Exchange Rate Dynamics: An Application of Asymmetric Volatility Models. Bank of Jamaica. Working Paper WP2004/03.

Lubik, Thomas, \& Frank, Schorfheide, (2007). Do central banks respond to exchange rate movements? A structural investigation. Journal of Monetary Economics, 54, 1069-1087. http://dx.doi.org/10.1016/j.jmoneco.2006.01.009

Mandelbrot, B. (1963). The variation of certain speculative prices. Journal of Business, 36, 394-414. http://dx.doi.org/10.1086/294632

Mark, Nelson. (2009). Changing Monetary Policy Rules, Learning, and Real Exchange Rate Dynamics. Journal of Money, Credit, and Banking, 41, 1047-1070. http://dx.doi.org/10.1111/j.1538-4616.2009.00246.x

McKenzie, M.D. (1997). ARCH Modelling of Australian Bilateral Exchange Rate Data. Applied Financial Economics, 7, 147 - 164. http://dx.doi.org/10.1080/096031097333718

Meese, R., \& K. Rogoff. (1983). Empirical Exchange Rate Models of the Seventies: Do They Fit the Out of Sample?. Journal of International Economics, 14, 3-24. http://dx.doi.org/10.1016/0022-1996(83)90017-X

Milhoj, Anders. (1987). A conditional variance model for daily observations of an exchange rate. Journal of Business and Economic Statistics, 5, 99-103. http://dx.doi.org/10.2307/1391219

Miller, E. (1988). Why a Weekend effect?. Journal of Portfolio Management, 14, 42-48. http://dx.doi.org/10.3905/jpm.1988.409174

Nelson, D.B. (1991). Conditional heteroscedasticity in asset returns: a new approach. Econometrica, 59, 347-370. http://dx.doi.org/10.2307/2938260

Pavasuthipaisit, Robert. (2010). Should inflation-targeting central banks respond to exchange rate movements? Journal of International Money and Finance 29, pp 460-85. http://dx.doi.org/10.1016/j.jimonfin.2009.06.005

Pesaran, B., \& G. Robinson, (1993). The European exchange rate mechanism and the volatility of the sterling-deutschmark exchange rate. Economic Journal, 103, 1418-1431. http://dx.doi.org/10.2307/2234474

Poon, S. (2005). A Practical Guide to Forecasting Financial Market Volatility. New Jersey, John Wiley Sons, Inc. 
Rachev, S.T., Mittnik, S., Fabozzi, F. J., Focardi, S., \& Jasic, T. (2007). Financial Econometrics: From Basics to Advanced Modelling Techniques. John Willey and Sons, Inc.

Taylor, S. J. (1987). Forecasting the Volatility of Currency Exchange Rates. International Journal of Forecasting, 3, 159 - 70. http://dx.doi.org/10.1016/0169-2070(87)90085-9

Theobald, M., and Price, V. (1984). Seasonality Estimation in Thin Markets. Journal of Finance, 39, 377- 392. http://dx.doi.org/10.2307/2327866

Tiwari, Rajnish. (2003) Post-crisis Exchange Rate Regimes in Southeast Asia: An Empirical Survey of de-facto Policies. Seminar Paper, University of Hamburg, online available: http://www.rrz.uni-hamburg.de/RRZ/R.Tiwari/papers/exchange-rate.pdf, (Seotember, 2008).

Tsay, R.S. (2002). Analysis of Financial Time Series. New York, John Wiley \& Sons Inc. http://dx.doi.org/10.1002/0471264105

Tse, Y.K., \& Tsui, A.K. (1997). Conditional Volatility in Foreign Exchange Rates: Evidence from the Malaysian Ringgit and Singapore Dollar. Pacific Basin Finance Journal 5, 345-356. http://dx.doi.org/10.1016/S0927-538X(97)00002-4

Wang, P. (2003). Financial Econometrics: Methods and Models. Routledge, London and New York

Wang, T. Alan. (2006). Does Implied Volatility of Futures Currency Option Imply Volatility of Exchange Rates?. Elsevier, Physica, 374, 773-782.

Yoon, S., \& K. S. Lee. (2008). The Volatility and Asymmetry of Won/Dollar Exchange Rate. Journal of Social Sciences, 4, 7-9, 2008. http://dx.doi.org/10.3844/jssp.2008.7.9

\section{Notes}

Note 1. GARCH-M models (Engle et al., 1987), IGARCH model (Engle and Bollerslev 1986), Exponential GARCH model (Nelson, 1991), Threshold GARCH model Zakoian (1994) and (Glosten et al., 1993) and Power ARCH model (Ding et al., 1993), Components ARCH (Engle and Lee 1993).

Note 2. For more detail see for example Tsay 2002 and Poon, 2005.

Note. 3. For further reading on holidays and weekend effects see for example Theobald and Price (1984), Miller (1988), Abraham and Ikenberry (1994), and Cai et al. (2006).

Note 4. Maximum likelihood estimator (MLE) is the most popular method where parameters are chosen such that the probability of occurrence of data under its assumed density function is the maximum. MLE is widely used because it produces an asymptotically normal and efficient parameter estimates.

Note 5. In a normally distributed series, skewness is 0 and kurtosis is 3 . Positive or negative skewness indicates asymmetry in the series and less than or greater than 3 kurtosis coefficient suggest flatness and peakedness, respectively, in the data.

Note 6 . These tests examine whether we can predict the squared normalized residual by some variables observed in the past which are not included in the volatility model being used. If these variables can predict the squared normalized residual, then the variance model is misspecified.

Table 1. Descriptive Statistics of the exchange rate of the currencies against US dollar

\begin{tabular}{|l|c|c|c|c|l|l|l|l|l|}
\hline Currencies & Mean & Min. & Max. & S. D. & Currencies & Mean & Min & Max. & S. D. \\
\hline AED & 3.67 & 3.64 & 3.6735 & 0.0010 & MAD & 9.073 & 7.140 & 12.04 & 1.234 \\
\hline BHD & 0.38 & 0.36 & 0.3779 & 0.0026 & MUR & 256.3 & 219.6 & 289.4 & 12.86 \\
\hline DJF & 169.9 & 143.8 & 177.720 & 4.4620 & OMR & 0.383 & 0.370 & 0.387 & 0.001 \\
\hline DZD & 71.31 & 57.28 & 80.4162 & 3.7352 & QAR & 3.634 & 3.395 & 3.664 & 0.024 \\
\hline EGP & 5.283 & 3.408 & 6.3513 & 0.7889 & SAR & 3.748 & 3.698 & 3.765 & 0.004 \\
\hline IQD & 1775 & 1108 & 3124.00 & 757.9814 & SOS & 2033 & 1222 & 3179 & 637.3 \\
\hline JOD & 0.745 & 0.694 & 0.7100 & 0.0021 & SYP & 47.99 & 40.95 & 58.49 & 2.665 \\
\hline KWD & 0.291 & 0.262 & 0.3089 & 0.0117 & TND & 1.334 & 1.131 & 1.522 & 0.083 \\
\hline LBP & 1485 & 1429 & 1514.30 & 19.8358 & YER & 191.4 & 164.2 & 239.2 & 15.09 \\
\hline LYD & 1.116 & 0.459 & 1.3338 & 0.2678 & & & & & \\
\hline
\end{tabular}


Table 2. Descriptive Statistics of the exchange rate returns series

\begin{tabular}{|c|c|c|c|c|c|c|c|c|}
\hline & Mean & Min. & Max. & Std. D. & Skewness & Kurtosis & J-B & ADF \\
\hline AED & $-6.96 \mathrm{E}-06$ & -0.632 & 0.724591 & 0.0225 & 2.670328 & 494.4522 & $35417829^{*}$ & $-46.02^{*}$ \\
\hline BHD & -0.00016 & -4.924 & 4.977234 & 0.8438 & 0.007990 & 17.77734 & $32018.51^{*}$ & $-63.66^{*}$ \\
\hline DJF & 0.002436 & -3.152 & 9.940499 & 0.5163 & 3.945172 & 74.53601 & $759467.3^{*}$ & $-37.80^{*}$ \\
\hline DZD & -0.001177 & -4.405 & 5.355525 & 0.8596 & 0.184042 & 10.65667 & $8615.698^{*}$ & $-51.02^{*}$ \\
\hline EGP & 0.007399 & -11.06 & 15.60286 & 0.9212 & 1.953165 & 51.51488 & $347347.8^{*}$ & $-46.27^{*}$ \\
\hline IQD & -0.026664 & -74.19 & 5.074177 & 1.3968 & -42.55365 & 2261.854 & $7.49 \mathrm{E}+08^{*}$ & $-48.52^{*}$ \\
\hline JOD & $8.06 \mathrm{E}-05$ & -1.392 & 1.445877 & 0.2069 & 0.111681 & 11.15080 & $9748.437^{*}$ & $-66.18^{*}$ \\
\hline KWD & -0.003065 & -2.386 & 2.907374 & 0.2332 & 0.493437 & 25.18613 & $72315.21^{*}$ & $-49.83^{*}$ \\
\hline LBP & 0.000412 & -5.001 & 4.950929 & 0.8745 & -0.137921 & 11.21966 & $9917.557^{*}$ & $-60.66^{*}$ \\
\hline LYD & -0.001922 & -9.884 & 1.22703 & 0.5915 & 1.239034 & 85.09331 & $989051.9^{*}$ & $-47.58^{*}$ \\
\hline MAD & -0.009803 & -4.162 & .133995 & 0.2273 & 0.152842 & 6.935277 & $2284.396^{*}$ & $-43.28^{*}$ \\
\hline MUR & 0.001398 & -11.11 & 11.50472 & 0.8087 & 0.627939 & 43.92586 & $245817.3^{*}$ & $-39.59^{*}$ \\
\hline OMR & $-5.17 \mathrm{E}-05$ & -3.504 & 3.166491 & 0.3227 & 0.147625 & 49.12274 & $311929.2^{*}$ & $-51.49^{*}$ \\
\hline QAR & $3.12 \mathrm{E}-06$ & -5.143 & .076545 & 0.6672 & 0.105014 & 31.81248 & $121728.5^{*}$ & $-50.46^{*}$ \\
\hline SAR & $-2.27 \mathrm{E}-06$ & -1.386 & .137430 & 0.759 & -0.981169 & 56.91341 & $426753.0^{*}$ & $-63.18^{*}$ \\
\hline SOS & -0.013901 & -20.19 & 8.616237 & 0.2415 & -1.284939 & 35.02021 & $151302.1^{*}$ & $-47.19^{*}$ \\
\hline SYP & -0.000244 & -12.64 & 20.38335 & 0.9099 & 2.431750 & 118.8036 & $1969779^{*}$ & $-39.72^{*}$ \\
\hline TND & -0.000794 & -15.14 & 14.82751 & 2.2879 & -0.049461 & 21.15078 & $48307.14^{*}$ & $-63.17^{*}$ \\
\hline YER & 0.006093 & -11.43 & 11.53460 & 0.4232 & 0.037140 & 34.58145 & $146242.9^{*}$ & $-60.58^{*}$ \\
\hline
\end{tabular}

Notes: 1 - Indicates that the results are statistically significant at the $1 \%$ level.

2- ADF test includes a constant term without trend.

Table 3. ARCH-LM Test for residuals of returns series

\begin{tabular}{|l|c|c|c|c|c|c|c|c|c|c|}
\hline Currencies & AED & BHD & DJF & DZD & EGP & IQD & JOD & KWD & LBP & LYD \\
\hline $\begin{array}{l}\text { ARCH-LM test } \\
\text { statistic }\end{array}$ & $1532^{*}$ & $1245^{*}$ & $487.9^{*}$ & $408.4^{*}$ & $456.9^{*}$ & 0.022 & $866.1^{*}$ & $385.3^{*}$ & $1579.7^{*}$ & 0.039 \\
\hline $\begin{array}{l}\text { Currencies } \\
\text { ARCH-LM test } \\
\text { statistic }\end{array}$ & $603.4^{*}$ & $815.9^{*}$ & $116.1^{*}$ & $639.9^{*}$ & $478.0^{*}$ & $77.3^{*}$ & $578.1^{*}$ & $1667.5^{*}$ & $1686.3^{*}$ & \\
\hline
\end{tabular}

Notes: $H_{0}$ : There are no ARCH effects in the residual series.

* Indicates significant at $1 \%$ significant level.

Table 4. Estimation results of GARCH(1,1) model

\begin{tabular}{|c|c|c|c|c|c|c|c|}
\hline \multirow{2}{*}{ Currencies } & \multirow{2}{*}{$\omega$} & \multirow{2}{*}{$\alpha$} & \multirow{2}{*}{$\beta$} & \multirow{2}{*}{$\alpha+\beta$} & \multirow{2}{*}{$\begin{array}{c}\text { Log } \\
\text { likelihood }\end{array}$} & \multicolumn{2}{|c|}{ ARCH-LM Test } \\
\hline & & & & & & statistic & Prob. \\
\hline AED & $8.50 \mathrm{E}-07 *$ & $0.111302 *$ & $0.904413^{*}$ & 1.015715 & 13897.79 & 14.26176 & 0.505777 \\
\hline BHD & $0.000533 *$ & $0.022216^{*}$ & $0.977682 *$ & 0.999898 & -1585.909 & 16.16764 & 0.370999 \\
\hline DJF & $0.000839 *$ & $0.023757 *$ & $0.979260^{*}$ & 1.003017 & -3329.159 & 18.74005 & 0.225756 \\
\hline DZD & $0.004040 *$ & $0.069104 *$ & $0.932407^{*}$ & 1.001511 & -5000.586 & 39.74372 & 0.000496 \\
\hline EGP & $0.022422 *$ & $0.068604 *$ & $0.902161 *$ & 0.970765 & -4606.610 & 0.485958 & 1.000000 \\
\hline JOD & $5.79 \mathrm{E}-05^{*}$ & $0.188803 *$ & $0.874751^{*}$ & 1.063554 & 3014.051 & 16.20451 & 0.368592 \\
\hline KWD & $0.000312 *$ & $0.053763 *$ & $0.943929 *$ & 0.997692 & 1223.468 & 17.12639 & 0.311365 \\
\hline LBP & $0.002419 *$ & $0.061709^{*}$ & $0.940003 *$ & 1.001712 & -3476.090 & 4.309008 & 0.996536 \\
\hline MAD & $0.002149 *$ & $0.039420 *$ & $0.959707^{*}$ & 0.999127 & -5223.059 & 69.59486 & 0.000000 \\
\hline MUR & $0.006964 *$ & $0.071859 *$ & $0.919355^{*}$ & 0.991214 & -3507.733 & 4.692976 & 0.994422 \\
\hline OMR & $0.001729 *$ & $0.080914 *$ & $0.916108^{*}$ & 0.997022 & 202.5211 & 5.522989 & 0.986696 \\
\hline QAR & $0.002158^{*}$ & $0.051709 *$ & $0.952221 *$ & 1.00393 & -1641.817 & 0.777535 & 1.000000 \\
\hline SAR & $1.86 \mathrm{E}-06 \mathrm{v}$ & $0.142810^{*}$ & $0.888220^{*}$ & 1.03103 & 11060.68 & 6.282886 & 0.974594 \\
\hline SOS & $0.025923 *$ & $0.071293 *$ & $0.900938^{*}$ & 0.972231 & -4705.430 & 0.058244 & 1.000000 \\
\hline SYP & $0.032733 \mathrm{v}$ & $0.152505^{*}$ & $0.887726^{*}$ & 1.040231 & -5987.829 & 0.486776 & 1.000000 \\
\hline TND & $0.006702 *$ & $0.170539 *$ & $0.873210^{*}$ & 1.043749 & -5706.664 & 1.487619 & 0.999996 \\
\hline YER & $0.002289 *$ & $0.188023 *$ & $0.914639 \mathrm{v}$ & 1.102662 & -2259.343 & 0.135458 & 1.000000 \\
\hline
\end{tabular}

Note: * Denotes significance at the $1 \%$ level. 
Table 5. Estimation results of EGARCH(1,1) model

\begin{tabular}{|c|c|c|c|c|c|c|c|}
\hline \multirow{2}{*}{ Currencies } & \multirow{2}{*}{$\omega$} & \multirow{2}{*}{$\alpha$} & \multirow[t]{2}{*}{$\beta$} & \multirow{2}{*}{$\gamma$} & \multirow{2}{*}{$\begin{array}{c}\text { Log } \\
\text { likelihood }\end{array}$} & \multicolumn{2}{|c|}{ ARCH-LM Test } \\
\hline & & & & & & statistic & Prob. \\
\hline AED & $-13.03336^{*}$ & $0.313838^{*}$ & $-0.519609 *$ & $-0.123702 *$ & 12258.67 & 1257.77 & 0.0000 \\
\hline BHD & $-0.078087 *$ & $0.101849^{*}$ & $0.988342 *$ & $-0.200766^{*}$ & -740.0006 & 0.12617 & 1.0000 \\
\hline DJF & $-0.049974 *$ & $0.022241 *$ & $0.967575^{*}$ & $-3418.323 *$ & -3418.323 & 5.06858 & 0.9915 \\
\hline DZD & $-0.101055^{*}$ & $0.167210^{*}$ & $0.990183^{*}$ & $-0.031086 *$ & -5066.862 & 40.2992 & 0.0000 \\
\hline EGP & $-0.100968^{*}$ & $0.132437^{*}$ & $0.954535^{*}$ & $-0.183590 *$ & -4479.508 & 12.2535 & 0.6597 \\
\hline JOD & $-0.338132 *$ & $0.357846^{*}$ & $0.957328^{*}$ & $0.019610^{*}$ & 2773.870 & 30.4282 & 0.0104 \\
\hline KWD & $-0.106158^{*}$ & $0.094616^{*}$ & $0.983337^{*}$ & $-0.065332 *$ & 1101.609 & 45.9084 & 0.0000 \\
\hline LBP & $-0.045539^{*}$ & $0.050058^{*}$ & $0.988804 *$ & $-0.190857^{*}$ & -3515.859 & 1.73969 & 0.9999 \\
\hline MAD & $-0.063991 *$ & $0.091828 *$ & $0.995378^{*}$ & $-0.086207^{*}$ & -5197.239 & 127.997 & 0.0000 \\
\hline MUR & $-0.117139^{*}$ & $0.174755^{*}$ & $0.956798^{*}$ & $-0.045725^{*}$ & -3725.470 & 26.7005 & 0.0312 \\
\hline OMR & $-0.029562 *$ & $-0.008418^{*}$ & $0.992434 *$ & $-0.210764 *$ & 1119.458 & 19.2269 & 0.2036 \\
\hline QAR & $-0.025742 *$ & $-0.100117^{*}$ & $0.990081^{*}$ & $-0.415596^{*}$ & -1108.082 & 0.70049 & 1.0000 \\
\hline SAR & $-0.146521^{*}$ & $0.151156^{*}$ & $0.992861 *$ & $-0.206656^{*}$ & 11059.13 & 8.31246 & 0.9106 \\
\hline SOS & $-0.088910^{*}$ & $0.153635^{*}$ & $0.938346^{*}$ & $-0.074651^{*}$ & -4943.147 & 0.03083 & 1.0000 \\
\hline SYP & $0.789230^{*}$ & $0.035457^{*}$ & $-0.658564 *$ & -0.190590 & -7202.369 & 11.8453 & 0.5643 \\
\hline TND & $-0.196725^{*}$ & $0.348268^{*}$ & $1.004092 *$ & $-0.130239 *$ & -5784.852 & 6.50237 & 0.9700 \\
\hline YER & $-0.104012 *$ & $0.230964 *$ & 0.971554* & $-0.088034 *$ & -2292.899 & 0.70695 & 1.0000 \\
\hline
\end{tabular}

Note: * Denotes significance at the $1 \%$ level.

Table 6. Results of asymmetric test

\begin{tabular}{|c|c|c|c|c|}
\hline \multirow{2}{*}{ Currencies } & Intercept & Sign bias & \multicolumn{2}{|c|}{ Size bias } \\
\cline { 2 - 5 } & $\varphi_{0}$ & $\varphi_{1}$ & $\psi_{3}$ & $0.323^{* * *}$ \\
\hline AED & $1.050^{* *}$ & $-0.134^{*}$ & $-1.213^{* * *}$ & $0.229^{* *}$ \\
\hline BHD & $1.123^{* *}$ & $-0.211^{*}$ & $-1.021^{* * *}$ & $0.125^{*}$ \\
\hline DJF & $1.032^{* *}$ & 0.143 & -0.373 & $0.201^{* *}$ \\
\hline DZD & 1.832 & 0.311 & $-0.972^{*}$ & $0.314^{* *}$ \\
\hline EGP & $0.873^{* * *}$ & $-0.251^{* *}$ & $-1.011^{*}$ & -0.033 \\
\hline JOD & 1.921 & 0.921 & 0.009 & $0.129^{* * *}$ \\
\hline KWD & $0.832^{* * *}$ & $-0.397^{* *}$ & $-1.072^{* * *}$ & 0.003 \\
\hline LBP & $1.527^{*}$ & 0.432 & -0.032 & $0.192^{*}$ \\
\hline MAD & $1.493^{*}$ & $0.140^{*}$ & -0.004 & $0.292^{* *}$ \\
\hline MUR & $0.932^{* * *}$ & $-0.137^{*}$ & $-0.629 * *$ & $0.310^{* *}$ \\
\hline OMR & $0.864^{* * *}$ & $-0.235^{*}$ & $-1.219^{*}$ & $0.352^{* *}$ \\
\hline QAR & $0.821^{* * *}$ & $-0.211^{*}$ & $-1.327^{* * *}$ & $0.157^{* * *}$ \\
\hline SAR & $0.759^{* * *}$ & $-0.241^{* *}$ & $-1.038^{* * *}$ & 0.001 \\
\hline SOS & $1.321^{*}$ & -0.143 & -0.017 & $0.148^{*}$ \\
\hline SYP & $1.092^{* *}$ & $0.129^{*}$ & $-0.782^{*}$ & $0.102^{*}$ \\
\hline TND & $1.021^{*}$ & $-0.232^{* *}$ & -0.078 & 0.007 \\
\hline YER & $1.211^{*}$ & $-0.141^{*}$ & -0.023 & \\
\hline
\end{tabular}

$* * *, * *, *$ indicate that the null hypothesis can be rejected at the $1 \%, 5 \%$ and $10 \%$ levels respectively. 

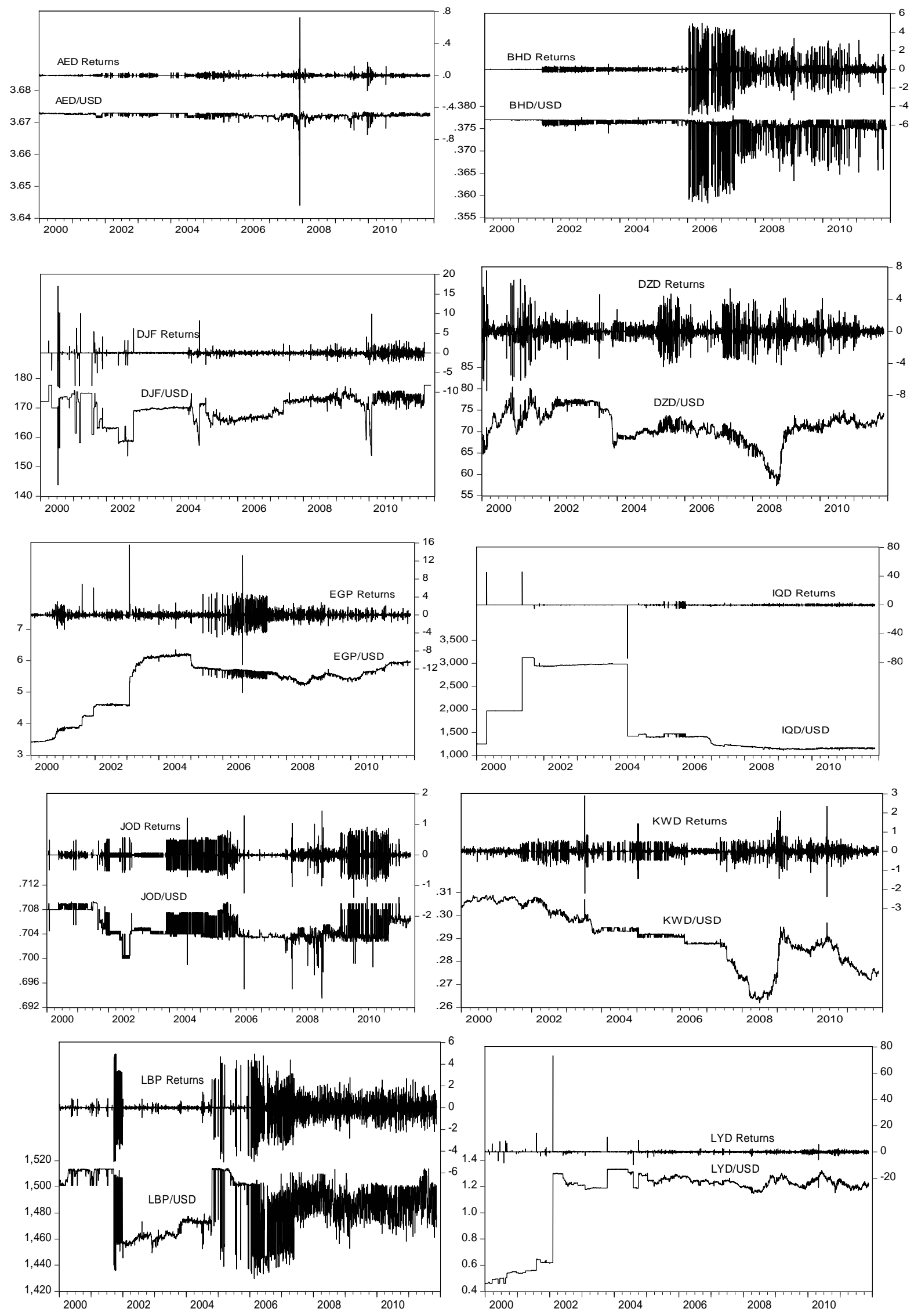

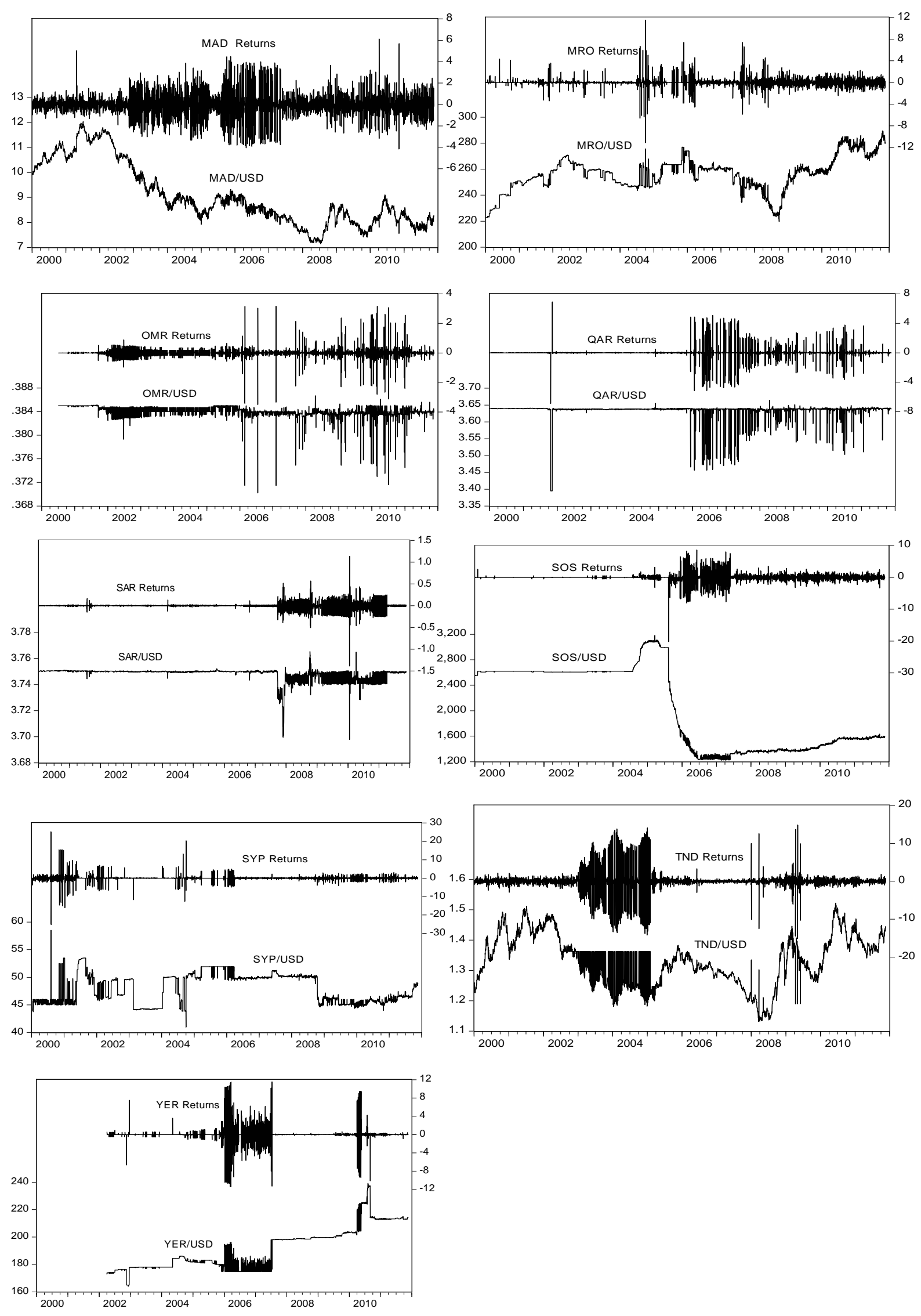

Figure 1. Plots of Exchange Rates and its Returns (2000-2011) 